\title{
REPRESENTASI NILAI KESETIAAN DALAM NOVEL NEGERI DI UJUNG TANDUK KARYA TERE LIYE
}

\author{
Saptiana Sulastri \\ Program Studi Pendidikan Bahasa dan Sastra Indonesia \\ IKIP PGRI Pontianak \\ Jalan Ampera No. 88 Pontianak 78116 \\ email korespondensi: saptianasulastri292@gmail..com
}

\begin{abstract}
Abstrak
Penelitian ini mendeskripsikan nilai kesetiaan dalam novel Negeri di Ujung Tanduk karya Tere Liye dengan metode penelitian yang digunakan deskriptif kualitatif. Sementara itu, teknik pengumpulan data menggunakan teknik studi dokumenter dengan alatnya human instrument. Adapun teknik analisis data yang digunakan dalam penelitian ini adalah kajian isi. Hasil analisis dari penelitian ini sebagai berikut. (1) kesetiaan terhadap peraturan dan kewajiban. (2) kesetiaan terhadap keteguhan hati, (3) kesetiaan terhadap pendirian/janji.
\end{abstract}

Kata Kunci: Representasi, nilai kesetiaan, novel Negeri di Ujung Tanduk

\begin{abstract}
This study describes the value of loyalty in the novel Negeri di Ujung Tanduk by Tere Liye. The research method used is descriptive qualitative. Meanwhile, data collection techniques used documentary study techniques with human instruments. The data analysis technique used in this study is the content study. The results of the analysis of this study are as follows. (1) loyalty to regulations and obligations. (2) loyalty to determination, (3) loyalty to the establishment / promise.

Keywords: Representation, the value of loyalty, the novel Negeri in Ujung Tanduk
\end{abstract}

\section{PENDAHULUAN}

Karya sastra merupakan gambaran kehidupan bermasyarakat, yang selayaknya dapat dinikmati, dipahami, dan dapat dimanfaatkan dalam kehidupan bermasyarakat. Karya sastra tergolong sebagai karya imajinatif, karena karakter di dalam karya sastra bukan tokoh-tokoh sejarah dalam kehidupan nyata. Tokoh-tokoh dalam karya sastra itu merupakan hasil ciptaan atau rekaan. Simarmata (2015:112) menjelaskan peristiwa yang terjadi diangkat dan dituangkan melalui daya imajinasi pengarang. Kajian tentang 
karya sastra sastra terkait dengan kajian tentang manusia, tentang kehidupan, tentang budaya, tentang ideologi, tentang perwatakan, bukan menyangkut masalah-masalah lain yang lebih luas terkait dengan kehidupan manusia. Pada dasarnya, karya sastra melalui rekaan pada tokoh dalam karya satra yang berhubungan dengan kajian tentang manusia tersebut terdapat nasihat, pedoman, dan ajaran dengan harapan agar pembaca dapat meneladani perbuatan yang baik melalui amanat atau pesan yang ada dalam sebuah karya sastra.

Karya sastra merupakan sarana yang digunakan pengarang untuk melukiskan keadaan yang terjadi di masyarakat. Karya sastra merupakan dunia imajinatif artinya, hasil kreasi pengarang setelah merefleksi lingkungan sosial dalam kehidupannya. Karya sastra dapat menjadi sumber inspirasi dan pendorong kekuatan moral bagi proses perubahan dalam masyarakat. Karya sastra yang mempunyai fungsi menyampaikan ide-ide atau gagasan seorang pengarang novel, puisi, dan drama.

Karya sastra sangat merujuk pada struktur yang kompleks yang satu diantaranya adalah fiksi. Fiksi menawarkan karya sastra yang bersifat imajinatif yang dilandasi kesadaran dan tanggung jawab dari segi kreativitas sebagai karya seni. Fiksi terdapat hasil dialog, reaksi pengarang terhadap lingkungan dan kehidupan. Cerita dalam sastra berdasarkan pengalaman hidup, pengamatan, pemahaman, dan penghayatan terhadap berbagai peristiwa kehidupan yang secara faktual dijumpai dimasyarakat, maka dapat dipandang sebagai salah satu interpretasi terhadap kehidupan itu sendiri.

Sastra berbicara tentang hidup dan kehidupan, tentang berbagai persoalan hidup manusia, tentang kehidupan di sekitar manusia, tentang kehidupan pada umumnya, yang semuanya diungkapkan dengan cara dan bahasa yang khas. Sehingga sastra berarti alat maupun sarana untuk mengajar baik itu berupa buku petunjuk, buku instruksi atau pengajaran (Teuuw, 2015: 20). Pengungkapkan yang digunakan sastra berbeda dengan cara-cara pengungkapan yang telah menjadi kebiasaan. Dalam bahasa sastra terkandung unsur dan tujuan keindahan yang lebih dikenal dengan estetis. Bahasa sastra p-ISSN 2089-2810 
jika dipahami secara mendalam lebih bernuansa keindahan dari pada kepraktisan (Nurgiyantoro, 2010: 2-3). Adapun genre karya sastra, yaitu genre prosa, genre puisi, dan genre drama, maka genre prosa lah, khususnya novel yang dianggap dominan dalam menampilkan unsur-unsur yang berupa nilai-nilai.

Novel merupakan bagian dari karya sastra. Novel adalah cerminan cerita nyata yang dibangun oleh dua unsur yaitu intrinsik dan ekstrinsik. Dalam hal ini, peneliti menggali lebih dalam dari satu unsur yaitu unsur ekstrinsik cerita yang ingin disampaikan pengarang dapat menarik untuk dibaca. Novel yang ditampilkan harus menarik pembaca seperti lewat pengolahan bahasa yang digunakan oleh peneliti agar pembaca dengan mudah memahami cerita yang ada di dalam novel serta memetik pelajaran atau nilai positif yang terdapat di dalamnya satu diantaranya adalah nilai kesetiaan.

Nilai kesetiaan adalah keteguhan hati, ketaatan (dalam keluargaan, persahabatan, perhambaan, dan sebagainya). Kesetiaan merupakan nilai moral yang lain, tapi harus diterapkan pada nilai manusiawi yang lebih umum, misalnya cinta tanah air, hormat, patuh, dan disiplin dalam melaksanakan peraturan. Kesetiaan mengacu kepada penyerahan diri pada suatu konsep relasi dalam kehidupan sosial. Budiyono (2007:30) mengatakan bahwa kesetiaan adalah orang yang berpendirian teguh, taat dengan perjanjian atau keputusan hasil musyawarah bersama, taat pada orang tua, keluarga, suku dan bangsa, dan tidak mudah terbujuk oleh orang lain atau harta. Kesetiaan mengandung aspek-aspek kebersamaan, solidaritas, dan empati. Solidaritas yang merupakan bagian dari kesetiaan adalah kata lain dari kasih, yang menggerakkan kaki, tangan, hati dan seluruh kepribadian manusia. Tujuannya adalah berbagi kehidupan dengan sesama yang menderita, dan menolong kebangkitannya untuk memperoleh kebebasan, keadilan, dan hak serta martabatnya.

Salah satu faktor yang mendukung ketercapaian tujuan kehidupan bersama adalah sikap setia. Setia terhadap apa yang telah menjadi p-ISSN 2089-2810 
kesepakatan bersama. Berpegang teguh atas apa yang diucapkan. Budiyono (2007:99) menjelaskan ciri-ciri kesetiaan adalah sebagai berikut: (1) kesetiaan terhadap peraturan dan kewajiban. Misalnya bagaimanapun berat tugas yang harus dijalankan, tetapi harus tetap setia (patuh dan taat) melaksanakannya, (2) kesetiaan terhadap keteguhan hati, (3) kesetiaan terhadap pendirian/janji, (4) kesetiaan terhadap tata hukum Indonesia.

Esensi dari sebuah nilai kesetiaan tercermin dari sikap mental yang dimiliki seseorang atau sebuah komunitas, berusaha memberikan yang terbaik bagi sesama, peka terhadap lingkungan sosialnya sehingga mendorong untuk peduli melakukan perbuatan bagi kepentingan lingkungan sosialnya tersebut. Dengan hal inilah sebuah hubungan atau relasi akan terjalin secara harmonis, karena didasarkan kesadaran dan kerelaan untuk taat pada masing-masing faktor yang dijadikan objek untuk setia. Tanpa peduli hal yang akan dijalankan terasa berat.

Satu di antara novel yang mengangkat nilai kesetiaan di dalamnya adalah novel Negeri di Ujung Tanduk karya Tere Liye. Novel ini mengajak pembaca berpikir dalam menghadapi kehidupan kita sebagai manusia harus memiliki sikap setia terhadap janji, teguh dalam pendirian, dan menanamkan rasa kepedulian terhadap sesama.

Novel Negeri di Ujung Tanduk karya Tere Liye terdiri dari 360 halaman, yang diterbitkan oleh PT Gramedia Pustaka Utama, di Jakarta, April 2013 merepresentasikan nilai kesetiaan dalam novelnya. Kelebihan novel Negeri di Ujung Tandukkarya Tere Liye kisah penceritaannya yang sangat menarik untuk kita ketahui, yaitu perjuangan yang dilakukan Thomas untuk menguap kasus-kasus yang terjadi di lingkungan pekerjaannya. Tujuan tersebut dilakukannya untuk memenangkan partai politik demi terciptanya pemimpin yang jujur. Novel ini sangat bagus, tuturannya mengalir, menyentuh, mencerahkan, dan bahasa yang digunakan tidak berbelit-belit membuat kita mudah untuk memahami cerita dari novel Negeri di Ujung Tanduk karya Tere Liye. 
Ada beberapa pendekatan yang dapat dilakukan untuk mengkaji karya sastra. Pengkajian karya sastra dapat dilakukan dengan pendekatan sosiologi sastra. Akbar, dkk. (2013:54) menjelaskan sosiologi sastra merupakan pendekatan yang menelaah tentang hubungan antara realitas sosial yang ada dalam masyarakat. Sapardi Djoko Damono (Santosa dkk, 2011:24) menyebutkan ada dua hal utama dalam telaah sosiologi sastra adalah pendekatan yang berdasarkan pada anggapan bahwa sastra merupakan cerminan proses sosial ekonomi dan pendekatan yang mengutamakan teks sastra sebagai bahan penelaahan yang kemudian dicari aspek-aspek sosial, baik itu aspek sosial ekonomi, agama, dan budaya dari karya sastra tersebut. Sejalan dengan itu, Semi mengungkapkan bahwa pendekatan sosiologis merupakan pencerminan kehidupan masyarakat dan realitas sosial (Semi, 2012:73).

Penelitian serupa juga pernah dilakukan oleh Annisa dalam judulnya "Representasi Nilai Kesetiaan Anak Kepada Orang Tua dalam Film Animasi Spirited Away karya Miyazaki Hayao". Perbedaan penelitian ini dengan sebelumnya terletak pada objeknya, penelitian sebeumnya berusaha merepresentasikan nilai kesetiaan anak kepada orang tua dalam pandangan budaya Jepang. Sementara itu, dalam penelitian ini peneliti berusaha merepresentasikan nilai kesetiaan yang ada dalam novel Ngeri di Ujung Tanduk karya Tere Liye.

Berdasarkan beberapa alasan yang telah dikemukakan, maka penelitian ini perlu dilakukan, karena dapat mengangkat khasanah sastra dan menanamkan nilai positif khususnya nilai kesetiaan. Adapun permasalahan yang diangkat dari penelitian ini adalah mengenai Representasi Nilai Kesetiaan dalam Novel Negeri di Ujung Tanduk Karya Tere Liye

\section{METODE}

Penelitian ini menggunakan metode deskriptif berupa kata-kata tertulis yang terdapat dalam novel. Taylor (Darmadi, 2014:287) mendefinisikan penelitian kualitatif sebagai prosedur penelitian yang menghasilkan data p-ISSN 2089-2810 
deskriptif berupa kata-kata tertulis atau lisan dari orang-orang dan pelaku yang dapat diamati. Kegiatan yang dilakukan adalah membaca, mencermati, menafsirkan, dan menganalisis novel. Adapun rangkaian kegiatan yang dilakukan adalah membaca, mencermati, menafsirkan, dan menganalisis novel. Data yang digunakan adalah kutipan berupa narasi dan dialog yang berhubungan dengan nilai kesetiaan pada novel.

Sumber data dalam penelitian ini adalah Novel Negeri di Ujung Tanduk Karya Tere Liye. Penelitian ini menggunakan teknik pengumpulan data teknik studi dokumenter dengan mengambil data yang bersumber dari dokumen berupa Novel Negeri di Ujung Tanduk. Adapun alat yang digunakan dalam penelitian ini adalah peneliti sendiri (human instrument). Pendekatan yang digunakan dalam penelitian ini adalah pendekatan sosiologi sastra. Teknik pengecekan keabsahan data menggunakan triangulasi data. Adapun teknik analisis data yang dilakukan menggunakan teknik kajian isi atau content analysis melalui beberapa tahapan: (1) membaca novel secara seksama, (2) mengidentifikasi kutipan, kata atau kalimat yang merupakan data sesuai dengan permasalahan yang diteliti berupa representasi nilai kesetiaan yang terdapat dalam Novel Negeri di Ujung Tanduk, (3) Mengklasifikasikan data berbentuk tabel ke dalam kartu data, (4) mendeskripsikan dan menjabarkan data, dan (5) Menyimpulkan hasil analisis.

\section{HASIL DAN PEMBAHASAN}

Esensi dari sebuah nilai kesetiaan tercermin dari sikap mental yang dimiliki seseorang, peka terhadap lingkungan sosialnya sehingga mendorong untuk peduli melakukan perbuatan bagi kepentingan lingkungan sosialnya tersebut. Kesetiakawanan sosial adalah memberikan yang terbaik bagi orang lain. Melalui kesetiaan sebuah hubungan atau relasi akan terjalin secara harmonis, karena didasarkan kesadaran dan kerelaan untuk taat pada masingmasing faktor yang dijadikan objek untuk setia.

Berdasarkan analisis yang dilakukan, di dalam novel Negeri di

Ujung Tanduk karya Tere Liye terdapat kutipan-kutipan yang 
menggambarkan nilai kesetiaan pada diri tokoh. Hal ini berkaitan langsung dengan karakter para tokoh dalam menjalani kehidupan.

\section{Kesetiaan Terhadap Peraturan dan Kewajiban}

"Theo benar atas dua hal: pertama, ide hebatnya benarbenar gila; kedua, aku tidak bisa menolaknya. Bahkan aku menyetujuinya mentah-mentah. Deal kawan! aku akan mempersiapkan pertarungan terbesar untukmu, Thomas. Rileks, biar aku yang mengurusnya. (Liye, 2013:15)

Kutipan di atas menunjukan bahwa kesetiaan Theo terhadap sahabat nya yang ingin bertarung tidak sia-sia dia sendiri yang akan mempersiapkan pertarungan terbesar untuk sahabat nya yaitu Thomas. Thomas sangat beruntung memiliki sahabat seperti Theo, dia begitu baik dan peduli terhadap Thomas. Dan tidak ingin melihat temannya yang mau mengikuti pertarungan dengan sia-sia maka Theo akan selalu setia membantu Thomas untuk tetap berlatih dengan tujuan agar Thomas bisa memenangi tarung tersebut. Nilai kesetiaan tersebut mencerminkan bahwa Thomas yang setia terhadap peraturan dan kewajiban. Bagaimanapun berat tugas yang harus dijalankan, tetapi harus tetap setia (patuh dan taat) melaksanakannya. Sikap setia lainnya juga ditunjukkan oleh Maryam.

"Aku akan ikut denganmu, Thomas. Aku tahu diri, aku hanya wartawan bodoh, tapi aku berguna banyak. Aku memiliki cukup koneksi dan kenalan. Beri aku perintah, aku akan mengerjakannya dengan baik, sama seperti yang dilakukan Maggie stafmu. Aku tidak mau bersembunyi di sebuah tempat, menunggu semua selesai dan berharap baik-baik saja. Maryam menatapku, berkata serius,"(Liye, 2013:144-145)

Kutipan di atas menunjukkan bahwa Maryam tetap ingin ikut dengan Thomas untuk mengetahui apa yang sedang ingin Thomas lakukan dalam melawan musuhnya. Kutipan tersebut menunjukkan bahwa Maryam adalah gadis wartawan yang selalu setia dan selalu peduli terhadap Thomas. Maryam berusaha dengan berbagai cara menjelaskan p-ISSN 2089-2810 
bahwa dia akan mengerjakan perintah dari Thomas. Hal tersebut dilakukannya karena ingin menunjukkan keteguhan pendirian janjinya kepada Thomas. Walaupun berat tugasnya harus dijelaskan.

\section{Kesetiaan Terhadap Keteguhan Hati}

"Setelah berminggu-minggu di atas kapal, kami dekat satu sama lain. Berbagi cerita, berbagi makanan, berbagi apa pun, termasuk berbagi tugas yang disuruh oleh pemilik kapal. Itu perjalan hidup-mati, melintasi ribuan mil, melewati badai. Tanpa teman karib yang saling menjaga, kau tidak akan bertahan lama. Opa mendongak, menatap langit-langit pesawat jet, diam sejenak. (Liye, 2013:125)

Kutipan di atas menunjukan bahwa kesetiaan yang dimiliki para penghuni kapal yang ditahan oleh sekelompok para mafia, dengan kesetiaan yang dimiliki mereka, mereka saling berbagi segala tugas yang diperintah oleh pemilik kapal, saling berbagi makanan dan berbagi apa pun. Kesetiaan dalam bentuk keteguhan hati untuk tetap peduli sesama yang dimiliki oleh Opa nya Thomas terhadap temannya yang baru dikenal pada saat mereka ditahan oleh sekelompok mafia, membuat Opa begitu peduli terhadap sesamanya. Sikap setia lainnya juga ditunjukkan oleh tokoh Rudi.

"Hei sebentar Thom, Rudi ikut turun dari mobil ambulans. Aku menoleh, Rudi melepas jam tangan di pergelangan tangannya, menyerahkan kepadaku. Aku tahu kau selalu tergesa-gesa dalam setiap urusan, terus melirik pukul berapa. Mendengar cemas, melirik lagi jam. Aku memberimu kado kecil, Thomas, jam tangan milikku. Karena kau tidak punya, dirampas pasukan khusus Hong Kong SAR, mungkin jam milikiku berguna untuk melihat jam berapa sekarang. Silakan.” (Liye, 2013:224)

Kutipan tersebut mencerminkan bahwa Rudi sangat peduli dan setia terhadap Thomas. Rudi adalah sahabat nya Thomas yang selalu membantu Thomas. Keteguhan hati untuk tetap setia terhadap Thomas yang memberikan jam tangannya untuk Thomas, Rudi memberikan jam tangannya karena dia tahu bahwa Thomas selalu tergesa-gesa dalam setiap urusannya dan selalu menanya pukul berapa, maka dari itulah Rudi 
memberikan jam tangannya kepada Thomas. Kalimat tersebut sudah membuktikan adanya nilai kesetiaan Rudi terhadap temannya yang memberikan kado kecil yaitu jam tangan miliknya sendiri.

\section{Kesetiaan Terhadap Pendirian/Janji}

"Orang tua ini tidak melakukan apa pun, Tommi. Hanya menunaikan kewajiban sebagai seorang teman. Kau tidak mungkin membiarkan teman senasib menderita sendirian. Maka aku merawat Chai Ten. Mencarikan selimut dari karung goni tebal yang bau dan kotor. Memberikan jatah makananku kepadanya. Memberikan air tawar yang susah payah didapat dari hujan turun. Membuat ramuan obat semampuku dari sisa-sisa logistik pemilik kapal nelayan. Menemaninya siang dan malam, menghibur nya, memberikan semangat kami berdua akan melalui hari-hari sulit tersebut, tiba di negeri yang lebih baik. (Liye, 2013:127)

Kutipan di atas menunjukan bahwa Om Liem paman nya Thomas sangat setia dan peduli kepada Chai Ten yaitu sahabatnya dengan kesetiaannya dan kepeduliaannya Om Liem pun akan merawat Chai Ten, memberikan jatah makanan nya kepadanya dan Om Liem pun harus membuat ramuan obat untuk temannya itu. Dengan melihat temannya yang lagi sakit Om Liem pun tetap pendirian dan berjanji memberikan semangat untuk temannya agar cepat pulih dari sakitnya. Sikap setia lainnya juga ditunjukkan oleh Maryam.

“Aku ikut denganmu, Thomas. Maryam punya pendapat lain, berkata sungguh-sungguh. Kau akan ikut dengan kadek dan Opa, Maryam. Aku menggeleng, ini berbahaya. Kau ingat apa yang dikatakan Opa dikapal beberapa menit sebelum kau mewawancaraiku tadi pagi. (Liye, 2013:144145)

Kutipan di atas menunjukkan bahwa Maryam ingin ikut dengan Thomas kemana pun Thomas akan pergi, walaupun dia mengetahui itu sangat berbahaya jika dirinya ikut dengan Thomas tetapi Maryam tetap saja ingin ikut. Kutipan menunjukkan bahwa kesetiaan Maryam kepada Thomas sahabatnya yang ingin ikut dengan Thomas, walaupun Thomas 
sudah meminta agar dia tidak ikut tetapi dia tetap saja memaksa agar dia bisa menemani Thomas dalam keadaan apapun. Hal tersebut menunjukkan sikap bahwa Thomas memiliki pendirian yang teguh terhadap janjinya.

\section{PEMBAHASAN}

Kesetiaan adalah keteguhan hati, ketaatan (dalam keluargaan, persahabatan, perhambaan, dan sebagainya). Kesetiaan merupakan nilai moral yang lain, tapi harus diterapkan pada nilai manusiawi yang lebih umum, misalnya cinta tanah air, hormat, patuh, dan disiplin dalam melaksanakan peraturan. Kesetiaan mengacu kepada penyerahan diri pada suatu konsep relasi dalam kehidupan sosial. Budiyono (2007:30) mengatakan bahwa kesetiaan adalah orang yang berpendirian teguh, taat dengan perjanjian atau keputusan hasil musyawarah bersama, taat pada orang tua, keluarga, suku dan bangsa, dan tidak mudah terbujuk oleh orang lain atau harta. Kesetiaan mengandung aspek-aspek solidaritas, empati dan bukan sebaliknya tak acuh, masa bodoh dengan orang lain atau egois. Solidaritas adalah kata lain dari kasih, yang menggerakkan kaki, tangan, hati dan seluruh kepribadian manusia. Tujuannya berbagi kehidupan dengan sesama yang menderita, dan menolong kebangkitannya untuk memperoleh kebebasan, keadilan, dan hak serta martabatnya. Empati merupakan sikap dan perasaan yang merasakan dan memahami kondisi emosi orang lain.

Sikap setia terhadap apa yang telah menjadi kesepakatan bersama merupakan faktor yang mendukung kelestarian dan tercapainya tujuan kehidupan bersama. Budiyono (2007:99) menjelaskan ciri-ciri kesetiaan adalah sebagai berikut. (1) kesetiaan terhadap peraturan dan kewajiban. Misalnya bagaimanapun berat tugas yang harus dijalankan, tetapi harus tetap setia (patuh dan taat) melaksanakannya, (2) kesetiaan terhadap keteguhan hati, (3) kesetiaan terhadap pendirian/janji, (4) kesetiaan terhadap tata hukum Indonesia.

Nilai kesetiaan tercermin dari sikap mental yang dimiliki seseorang atau sebuah komunitas, peka terhadap lingkungan sosialnya sehingga p-ISSN 2089-2810 
mendorong untuk peduli melakukan perbuatan bagi kepentingan lingkungan sosialnya tersebut. Esensi kesetiakawanan sosial adalah memberikan yang terbaik bagi orang lain. Melalui kesetiaan sebuah hubungan atau relasi akan terjalin secara harmonis, karena didasarkan kesadaran dan kerelaan untuk taat pada masing-masing faktor yang dijadikan objek untuk setia. Berdasarkan pendapat diatas bahwa nilai kesetiaan adalah suatu hal yang menjadi pegangan, serta kesetiaan yang dimiliki nilai yang baik di dalam suatu kehidupan, misalnya kesetiaan kepada negara, kesetiaan kepada lingkungan, dan kesetiaan kepada keluarga, dan kesediaan kepada atasan.

Berkenaan teori maka representasi nilai kesetiaan dalam novel Negeri di Ujung Tanduk Karya Tere Liye (1) kesetiaan terhadap peraturan dan kewajiban. Misalnya bagaimanapun berat tugas yang harus dijalankan, tetapi harus tetap setia (patuh dan taat) melaksanakannya, (2) kesetiaan terhadap keteguhan hati, (3) kesetiaan terhadap pendirian/janji, (4) kesetiaan terhadap tata hukum Indonesia.

\section{SIMPULAN}

Berdasarkan fokus penelitian dan hasil analisis yang telah peneliti jabarkan sebelumnya, maka simpulannya adalah sebagai berikut. 1) kesetiaan terhadap peraturan dan kewajiban. Misalnya, bagaimanapun berat tugas yang harus dijalankan, tetapi harus tetap setia (patuh dan taat) melaksanakannya, (2) kesetiaan terhadap keteguhan hati, (3) kesetiaan terhadap pendirian/janji.

\section{DAFTAR PUSTAKA}

Akbar, Syahrizal dkk. (2013). Kajian Sosiologi Sastra dan Nilai Pendidikan dalam Novel Tuan Guru Karya Salman Faris. Jurnal Pendidikan Bahasa dan Sastra No.1 Pp 54-68.

Budiyono, Kabul. (2007). Nilai-nilai Kepribadian dan Kejuangan Bangsa Indonesia. Cetakan Perdana. Bandung: Alfabeta

Darmadi, H. (2014). Metode Penelitian Pendidikan dan Sosial. Bandung: Alfabeta.

Teuuw. A. (2015). Sastra dan Ilmu Sastra. Bandung: Pustaka Jaya. 
Nurgiyantoro, B. (2010). Sastra Anak: Pengantar Pemahaman Dunia Anak. Yogyakarta: Gajah Mada University Press.

Simarmata, M. Y. (2016). Analisis Konflik Tokoh Utama Dalam Roman Tenggelamnya Kapal Van Der Wijck Karya Buya Hamka. Jurnal Pendidikan Bahasa, 4(1), 111-124.

Santosa, Wijaya Heru \& Sri Wahyuningtyas, dkk. (2011). Sastra: Teori dan Implementasi. Surakarta: Yuma Pustaka.

Semi, A. (2012). Metode Penelitian Sastra. Bandung: Angkasa. 